\title{
Identifikasi struktur dan perubahan lanskap Kota Banjarmasin di masa kesultanan (1526-1860)
}

\author{
Vera D Damayanti1,2* \\ 1. Departemen Arsitektur Lanskap, Fakultas Pertanian, Institut Pertanian Bogor, Indonesia \\ 2. Centre for Landscape Studies, Faculty of Arts, University of Groningen, the Netherlands \\ *Email: veradd@apps.ipb.ac.id
}

\begin{abstract}
Identifying the structure and transformation of Banjarmasin townscape during the Sultanate period (1526-1860): Banjarmasin city in the past was widely known as one of the main pepper producers in the Archipelago that turned the town to becoming one of the port cities in the Southeast Asia maritime trade network. As a port city, Banjarmasin showed a typical landscape character similar to other port cities in Southeast Asia. The physical landscape feature of this city inevitably was influenced by the economic factor on which trade was the primary income of the sultanate and its people. During the Sultanate period (15261860), the landscape of Banjarmasin was transformed as an impact of the political influence that related to the pepper trade, which involved foreign traders. The main objective of this study is to analyse the landscape changing of Banjarmasin during the Sultanate period by applying the historical method and spatial approach. In the spatial analysis, the landscape component of processes, space, material, and form was used to identify the landscape structure and its transformation. The result of the study shows that the landscape of Banjarmasin evolved in the following stages: (1) port-polity of Banjar sultanate (1526-1612); (2) secondary port-city of the sultanate (1612-1663); (3) primary port of the sultanate (1663-1787); (4) primary port of the Dutch in Southeast Kalimantan (1787-1860). With regard to the research process, the spatial dimension was not only obtained from the historical maps but also from written sources that indicated the location of activities or events.
\end{abstract}

Keywords: landscape history, port-city, early period city

\section{Pendahuluan}

Banjarmasin pada mulanya merupakan sebuah kesultanan yang berdiri di tahun 1526, dengan pusat pemerintahannya di distrik Banjarmasih yang terletak di muara Sungai Kuin. Saat ini secara adminsitratif areanya merupakan bagian dari Kelurahan Kuin Utara, Kecamatan Banjarmasin Utara. Di awal abad ketujuhbelas, pelabuhan kesultanan Banjarmasin dikenal sebagai penghasil lada yang penting di Nusantara yang menarik para pedagang asing, baik dari daratan Asia maupun Benua Eropa untuk berdagang lada. Semakin dikenalnya perdagangan lada di Banjarmasin telah menarik banyak pedagang yang bersaing untuk mendapatkan hak monopoli perdagangan lada dari sultan. Pada akhirnya, perdagangan dan persaingan ini menimbulkan konflik berlatar belakang politik ekonomi. Adanya berbagai persitiwa terkait perdagangan dan politiknya ini menjadi landasan penting dalam studi ini, baik untuk memformulasikan struktur lanskap maupun dalam analisis perubahan lanskap Banjarmasin.

Pengetahuan akan sejarah suatu lanskap merupakan salah satu aspek penting dalam merencana dan mendisain lanskap. Menurut Marcucci (2000), informasi kesejarahan berguna untuk mengetahui nilai sejarah suatu tempat atau elemen lanskap sehingga perlu untuk dilestarikan sebagai sebuah warisan (landscape as legacy). Data kesejarahan juga dapat menjadi inspirasi dalam membuat rencana atau rancangan lanskap dalam berbagai skala dan peruntukan. Lebih lanjut, pengetahuan sejarah lanskap berperan dalam membantu arsitek lanskap untuk lebih memahami karakter lanskap setempat, serta dapat menjadi alat analisis untuk memahami seluk-beluk berbagai permasalahan dalam lanskap, baik fisik, ekonomi, maupun sosial-budaya. Pengetahuan sejarah lanskap diperlukan terutama dalam menghadapi permasalahan lanskap yang dalam jangka panjang tak kunjung teratasi dikarenakan solusi yang dibuat tidak substansial. Untuk itu, proses yang mempengaruhi arah perubahan lanskap (keystone process) perlu diidentifikasi dalam penelusuran sejarah 
lanskap. Dalam studi ini, kategori proses budaya (cultural process) baik dalam konteks proses politik-ekonomi dan sosial-budaya, menjadi menjadi dasar dalam menganalisis perubahan lanskap.

Pemanfaatan sumber kesejarahan primer seperti arsip dan publikasi yang dibuat semasa periode kesejarahan dirasa masih kurang dimanfaatkan dalam studi lanskap di Indonesia. Oleh karenanya, salah satu hal yang mendasari penelitian ini yaitu mempelajari sejarah lanskap Banjarmasin dengan menggunakan data kesejarahan primer sebagai salah satu sumber data utama. Tujuan utama penelitian ini yaitu mempelajari perubahan lanskap di Banjarmasin di masa kesultanan. Diharapkan penelitian ini bermanfaat sebagai acuan studi penelusuran sejarah lanskap kota-kota lain di Indonesia.

\section{Metode}

Lokasi area studi yaitu Kota Banjarmasin di Kalimantan Selatan (Gambar 1). Studi ini dilakukan pada 2016-2017. Metode yang digunakan dalam penelitian ini adalah metode sejarah yang secara garis besar meliputi persiapan berupa pemilihan topik, dalam hal ini terkait dengan keystone processes; pengumpulan sumber kesejarahan primer dan sekunder; verifikasi secara triangulasi dan observasi lapang; interpretasi secara deskriptif dan spasial; penyusunan peta rekonstruksi dan penulisan narasi. Dalam studi ini yang dimaksud dengan data primer yaitu berbagai bentuk material atau sumber informasi yang dihasilkan semasa periode yang diteliti. Sedangkan data sekunder yaitu bebagai material atau sumber informasi yang menganalisis atau menginterpretasikan data primer. Dalam studi ini, data primer yang digunakan mencakup arsip dokumen, sketsa, peta, serta publikasi jurnal eksplorasi dan perjalanan. Sementara itu sumber data sekunder berupa publikasi terkait studi.

Dalam pengumpulan dan analisis data, komponen-komponen yang mengkarakterisasi lanskap yaitu proses, ruang, material, serta bentukan (Spirn, 1998) menjadi panduan dalam menelusuri data dari berbagai sumber kesejarahan dengan tujuan untuk menghasilkan data kualitatif. Berdasarkan keystone processes dan karakter lanskap yang terbentuk, kemudian diformulasikan tipologi lanskap Banjarmasin pada periode dimana keystone processes berlangsung. Produk akhir studi berupa satu seri peta rekonstruksi lanskap kota Banjarmasin di masa kesultanan serta narasi proses perubahan lanskapnya. Sebagai bahan dasar peta digunakan sumber peta-peta dari VOC dan pemerintah Hindia Belanda yang menggambarkan Banjarmasin di tahun 1700-1720, 1845, 1893, dan 1916. Atribut berbagai elemen lanskap dalam peta selain menjadi sumber data primer juga menjadi acuan dalam penggambaran rekonstruksi perubahan lanskap.

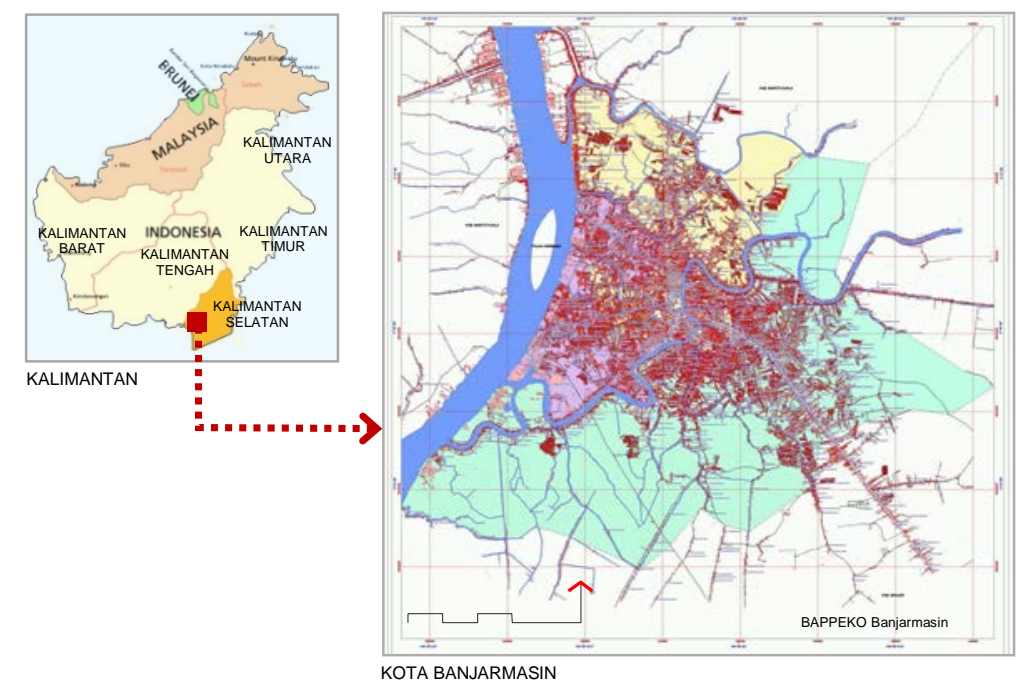

Gambar 1. Peta lokasi studi (Bappeko Banjarmasin, 2006)

\section{$3 \quad$ Hasil dan Pembahasan}

\subsection{Karakter lanskap alami}

Banjarmasin terletak sekitar $50 \mathrm{~km}$ dari muara Sungai Barito di Laut Jawa. Kota ini dilalui oleh sungaisungai besar yaitu Barito, Martapura dan Alalak. Banjarmasin dipengaruhi oleh iklim tropis dengan kelembapan 
dan suhu tinggi. Musim basah pada Oktober-April saat angin muson barat membawa angin yang lembab. Suhu udara Banjarmasin saat ini berkisar antara $28-35^{\circ} \mathrm{C}$. Pada masa kesultanan, variasi iklim berpengaruh terhadap kegiatan perekonomian, dimana musim hujan menentukan budidaya lada dan angin muson menentukan periode pelayaran para pedagang terutama dari luar Kalimantan (Ras, 1968; Knapen, 2001).

Daratan Banjarmasin terbentuk di atas dataran aluvial dan deposit gambut sebagai bagian dari Cekungan Barito (Barito Basin). Proses geologi pembentukan daratan Banjarmasin sangat dipengaruhi oleh adanya sungai-sungai. Pembentukan daratan terutama disebabkan proses progradasi pada periode Holocene sekitar 10.000 tahun yang lalu. Pembentukan daratan disebabkan oleh pengendapan sedimen dan akresi dari Pegunungan Meratus di muara Sungai Martapura dan Alalak yang pada saat itu letaknya dekat dengan pegunungan Meratus dan berupa teluk di Laut Jawa (Sumawinata, 1998).

Pembentukan daratan diikuti dengan evolusi lingkungan sedimentasi yang kemudian menentukan suksesi vegetasi. Suksesi lingkungan dimulai dari pantai berpasir, dataran pasang-surut dan pematang (levee), area rawa payau, rawa sungai, dan terakhir menjadi rawa gambut. Vegetasi awal yang tumbuh yaitu di dataran pasang surut dan pematang, berupa komunitas halophyt mangrove dengan spesies pionir seperti Avicennia, Sonneratia dan Rhizopora yang toleran kondisi salin. Ketika suksesi lingkungan mencapai puncaknya, terbentuk hutan rawa gambut di area belakang pematang sungai (backswamp) beserta vegetasi hutan riparian yang tumbuh di daerah pematang sungai (Sumawinata, 1998).

Kondisi jenis tanah pada area pematang yaitu Entisol, sementara di belakang pematang didominasi oleh Endoaquents yang mengandung tanah gambut Histosol. Kondisi subsoil berupa jenis tanah yang kaya akan pirit atau besi sulfida $\left(\mathrm{FeS}_{2}\right)$. Jenis tanah ini jika dibuang airnya menyebabkan pirit teroksidasi sehingga tanah menjadi sangat asam, dan memicu munculnya Alumunium Sulfat yang jika keduanya bereaksi membentuk Ferri-sulfat yang beracun bagi tanaman (Van Wijk, 1950).

Berdasarkan data di atas, karakter lanskap alami Banjarmasin sebelum adanya intervensi manusia terbentuk atas elemen sungai, pematang sungai (riparian), rawa, dan rawa gambut. Dengan kondisi tersebut maka di masa kesultanan area ini kurang sesuai untuk pertanian, terutama karena aspek kendala dari jenis tanah, hidrologi, dan keterbatasan pengetahuan dan teknologi.

\subsection{Berdirinya kesultanan Banjarmasin}

Munculnya kesultanan Banjarmasin di muara Sungai Kuin tak lepas dari dua kekuasan politik yang ada sebelumnya yaitu Nagara Dipa dan Nagara Daha. Kedua kerajaan ini bertempat di tepian Sungai Nagara, anak Sungai Barito di utara Banjarmasin. Pelabuhan dagang Nagara Dipa berada di Muara Rampiu, dan Nagara Daha di Muara Bahan (Marabahan), di Muara Sungai Nagara. Nagara Dipa yang diperkirakan berdiri di abad empatbelas, merupakan kerajaan Hindu yang mendapat pengaruh dari kerajaan Majapahit. Pada abad kelimabelas, pusat kekuasaan ini dipindahkan ke hilir yang menandai awal berdirinya Nagara Daha yang masih mengikuti tradisi Hindu (Ras, 1968; Ganie, 2011).

Pada tahun 1526, putra mahkota Nagara Daha yaitu Pangeran Samudera yang tersingkir dari keraton dikarenakan ambisi pamannya, mendirikan keraton di distrik Banjar di muara Sungai Kuin atas inisiasi Patih Masih -pemimpin daerah Banjar. la didukung oleh para patih dari daerah di sekitar Banjar seperti Balandean, Sarapat, Balitung, dan Kuwin. Pembentukan keraton ini berpengaruh terhadap perpindahan pusat perdagangan ke pelabuhan Banjarmasih di hilir Barito. Keraton Banjarmasih, yang kemudian dikenal dengan Banjarmasin, berubah menjadi sebuah kesultanan yang dipengaruhi agama Islam setelah berhasil menaklukkan Nagara Daha yang didukung 1000 pasukan dari Demak -kerajaan Islam yang kuat di Jawa kala itu. Kesultanan Banjarmasin menjadi sebuah kota-negara (city-state) yang pengaruh kekuasaannya meluas di Kalimatan Selatan, Timur dan sebagian Kalimantan Tengah (Ras, 1968; Saleh, 1982). Hal ini tak lepas dari peran pelabuhan Banjarmasin yang menguasai jalur perdagangan di selatan Kalimantan.

\subsection{Pelabuhan Banjarmasin memasuki 'era niaga'}

Pada abad kelima belas hingga tujuh belas kawasan Asia Tenggara memasuki 'era niaga' (the age of commerce) dimana aktivitas perdagangan meningkat signifikan. Fenomena ini tak hanya mendorong persebaran dan difusi budaya, teknologi, dan ideologi dari daratan Benua Asia ke kawasan kepulauan Asia Tenggara, namun juga mendorong munculnya kota-kota pelabuhan dagang dimana kapal-kapal pedagang merapat untuk singgah dan bertransaksi -termasuk diantaranya kota pelabuhan Banjarmasin. Lebih lanjut, 
kota-kota pelabuhan ini membentuk jalur perdagangan maritim (Gambar 2) terutama dipengaruhi oleh adanya aktivitas para pedagang Cina dan Timur Tengah (Reid, 1980; Reid, 1993).

Pelabuhan kesultanan Banjarmasin terlibat dalam jalur perdagangan maritim Asia Tenggara di awal abad ketujuhbelas. Masuknya pelabuhan Banjar dalam rute tersebut disebabkan kesultanan Banjar mulai dikenal sebagai produsen lada -yang ditanam di daerah hulu- oleh para pedagang asing. Rempah-rempah, terutama lada, merupakan salah satu komoditas dagang yang sangat penting kala itu (Ahyat, 2012). Kapalkapal dagang yang berkunjung ke pelabuhan Banjarmasin berasal dari kota-kota di Nusantara seperti misalnya Makassar, Sumbawa, Jawa, selain dari daratan Asia dan Eropa termasuk Cina, Persia, Siam, Belanda, Inggris, Portugis, Perancis, hingga Spanyol (Knapen, 2001).

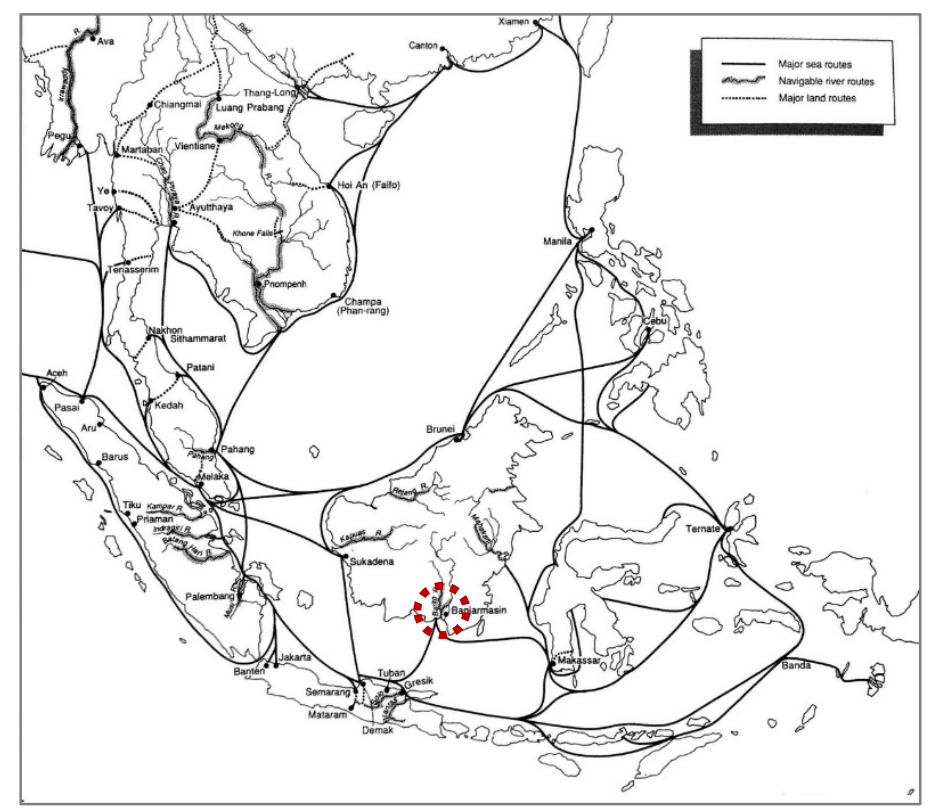

Gambar 2. Jalur perdagangan maritim di Asia Tenggara (Sumber: Reid, 1993)

\subsection{Transformasi lanskap Banjarmasin}

Selama lebih dari tiga abad berlangsungnya masa kesultanan (1529-1860) lanskap Banjarmasin berevolusi. Melaui identifikasi key process, yaitu kejadian terkait dengan aspek politik-ekonomi dan sosialbudaya, tahapan perubahan tipologi lanskap berdasarkan fungsi dan tatanan fisiknya secara kronologis ditampilkan pada Gambar 3.

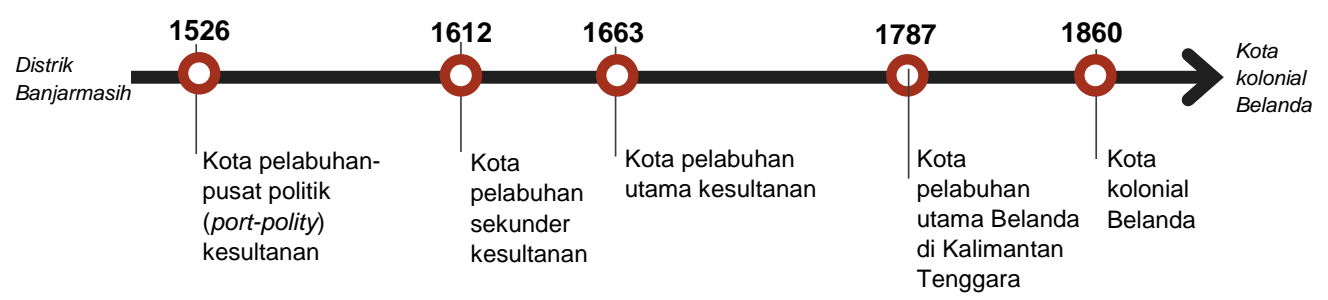

Gambar 3. Periodisasi perubahan lanskap Banjarmasin pada periode kesultanan (1526-1860)

\subsubsection{Kota pelabuhan-pusat politik (port-polity) (1526-1612)}

Pada awal periode kesultanan, keraton kesultanan Banjarmasin di muara Sungai Kuin memiliki pelabuhan dagang di hulu Sungai Pelambuan tak jauh dari keraton (Ras, 1968). Kala itu kota Banjarmasin berfungsi sebagai pusat politik dan sekaligus pusat ekonomi kesultanan (port-polity). Lanskap kotanya memiliki struktur linier di sepanjang Sungai Kuin, dimana seluruh fungsi yang menunjang kebutuhan kesultanan dan rakyatnya berlangsung didalamnya, baik fungsi politik, ekonomi, sosial dan budaya. Kompleks keraton dengan masjid kesultanan serta pelabuhan beserta rumah cukai dan institusi syahbandar, menjadi elemen lanskap 
utama. Dalam kawasan ini para elit kerajaan yang diantaranya juga berperan sebagai elit pedagang (orangkaya) bertempat tinggal. Sementara itu penduduk lokal dan pedagang dari luar Banjar tinggal di sekitarnya (Gambar 4).

Berdagang merupakan mata pencaharian utama kesultanan dan masyarakatnya. Kondisi ini dipengaruhi oleh keadaan lanskap alami yang didominasi oleh rawa dan sungai. Tanah berawa-gambut menyebabkan kegiatan pertanian sulit untuk dikembangkan. Sementara itu, posisi geografis Banjarmasin di hilir sangat sesuai sebagai pertemuan antara para pedagang dan pembeli dari hulu dan dari hilir.

Pematang sungai (riiver levee) merupakan area yang cenderung ekslusif dihuni oleh para elit dalam rumah-rumah panggung. Sementara itu sebagian besar masyarakat tinggal di atas sungai dalam rumah perahu atau yang dikenal sebagai rumah lanting. Sungai selain menjadi jalur transportasi utama, juga sebagai wadah bagi masyarakat dalam melakukan aktivitas sehari-hari. Salah satu peran sungai terutama memfasilitasi kegiatan ekonomi. Sungai Kuin menjadi akses utama menuju pelabuhan kesultanan, baik bagi pedagang dari kawasan hulu maupun hilir. Untuk memperlancar kegiatan perdagangan, pada bagian timur Sungai Kuin dibuat kanal -dikenal sebagai Antasan Kuin- yang menghubungkan Sungai Kuin dengan Sungai Martapura (Müller, 1857). Namun sejauh ini belum diketahui kapan tepatnya kanal tersebut dibuat. Masyarakat Banjar sendiri dikenal memiliki pengetahuan dan teknik tradisional menggali kanal (Subiyakto, 2004). Sementara itu, para pedagang di pasar lokal memanfaatkan badan sungai sebagai tempat transaksi sehingga tercipta pasar apung. Pasar apung merupakan salah satu fenomena yang umum dijumpai di kota-kota pelabuhan sungai di Asia Tenggara kala itu, dimana pedagangnya biasanya didominasi oleh perempuan (Reid, 1993).

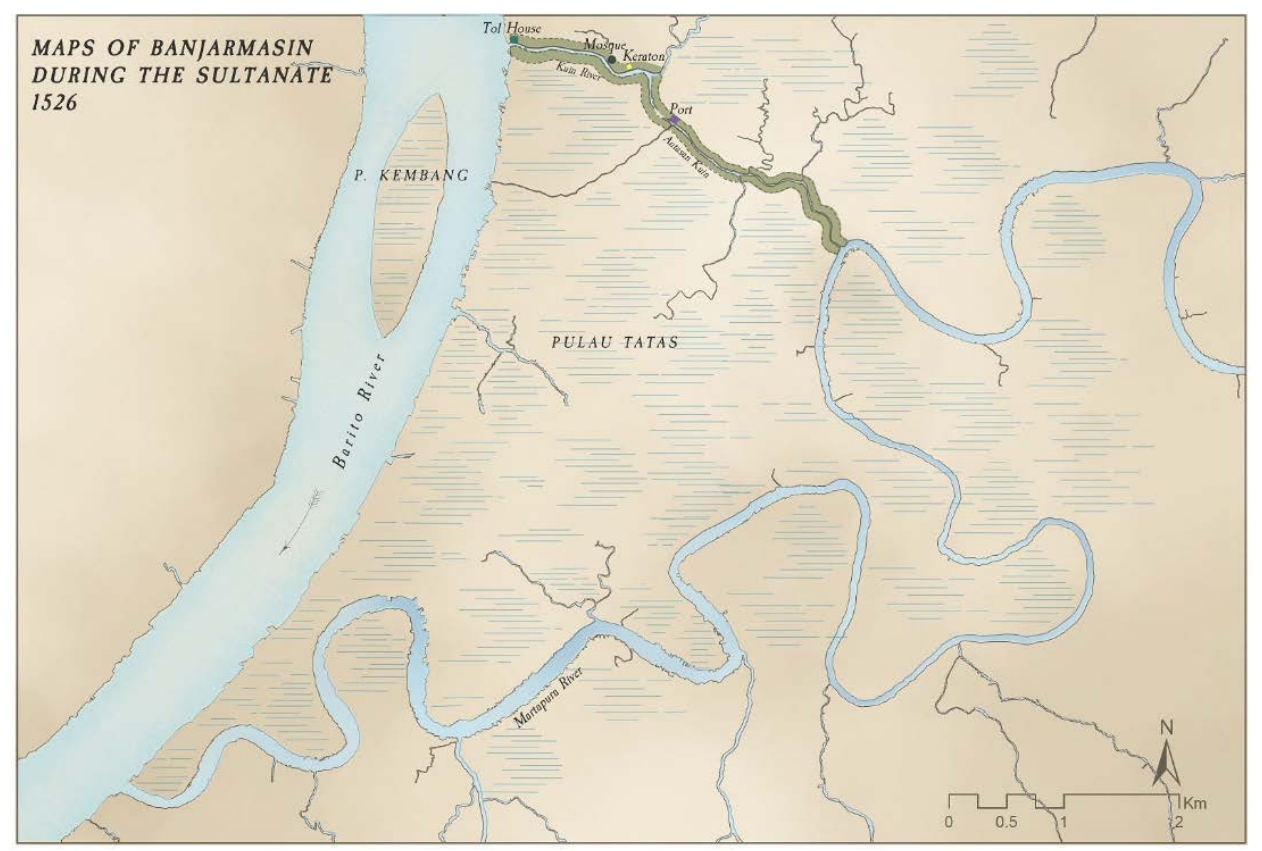

Gambar 4. Rekonstruksi peta Banjarmasin di awal pembentukan kesultanan

Terbentuknya pola linear kota tak lepas dari pengaruh kondisi fisik lanskap dimana pematang atau bantaran sungai terbatas lebarnya (Van Wijk, 1951). Sementara itu area di belakang pematang (backswamp) yang didominasi oleh rawa bukan menjadi alternatif ideal lahan permukiman karena untuk mengolah dan mendirikan struktur di atasnya dibutuhkan banyak tenaga kerja. Dengan rendahnya jumlah populasi di Pulau Kalimantan pada umumnya, dan dalam kawasan tersebut pada khususnya, akses terhadap terhadap tenaga manusia (manpower) di masa itu tidak merata, bergantung pada kondisi sosial-ekonominya (Reid, 1980)

3.4.2 Kota pelabuhan sekunder (secondary port-city) (1612-1663)

Pada tahun 1612 keraton Banjar di muara Sungai Kuin diserang oleh armada VOC (Vereeniging OostIndische Compagnie atau Persekutuan Dagang Hindia Timur). Penyerangan ini sebagai aksi pembalasan VOC terhadap pembantaian misi dagang VOC di tahun 1606 oleh sultan. Keraton Banjar kala itu hancur lebur akibat 
lokasinya mudah untuk diserang oleh musuh. Hal ini menjadi alasan utama ibu kota kesultanan dipindahkan. Beberapa alternatif lokasi pemindahan telah dilalui hingga pada akhirnya sultan yang berkuasa kala itu yaitu Sultan Marhum Panembahan (r. 1595-1620) memilih untuk menetap di Kayu Tangi, di pertengahan hulu-hilir Sungai Martapura. Pelabuhan dagang utama serta syahbandar dengan demikian dipindahkan ke Kayu Tangi (Van Dijk, 1862; Ras, 1968).

Kepindahan keraton dan pelabuhan dagang berdampak terhadap lanskap Banjarmasin di muara Sungai Kuin. Area tersebut dijuluki sebagai 'Banjar Lama' dan pelabuhan yang ada berubah menjadi pelabuhan sekunder. Meskipun demikian, pelabuhan ini tetap berperan penting dalam perdagangan kesultanan. Perahu besar para pedagang asing yang hendak berdagang lada biasanya berlabuh disini dan kemudian para utusan dagang berlayar dengan perahu yang lebih kecil ke keraton Kayu Tangi karena kondisi Sungai Martapura menyulitkan kapal besar berlayar ke hulu (Beckman, 1718).

Sebagai pelabuhan sekunder, perubahan lanskap yang terjadi cenderung pada elemen pengisi lanskap. Kondisi ini ditandai dengan hilangnya elemen kompleks keraton dan pelabuhan utama beserta rumah cukai dan syahbandar. Elemen yang menandai keberadaan pengaruh kesultanan yaitu kompleks makam sultan di sebelah utara bantaran Sungai Kuin yang menjadi persitirahatan tiga sultan pertama (Müller, 1857). Sementara itu struktur kota 'Banjar Lama' tidak berubah, berbentuk linier di kedua sisi Sungai Kuin yang didominasi oleh fungsi pemukiman (Gambar 5).

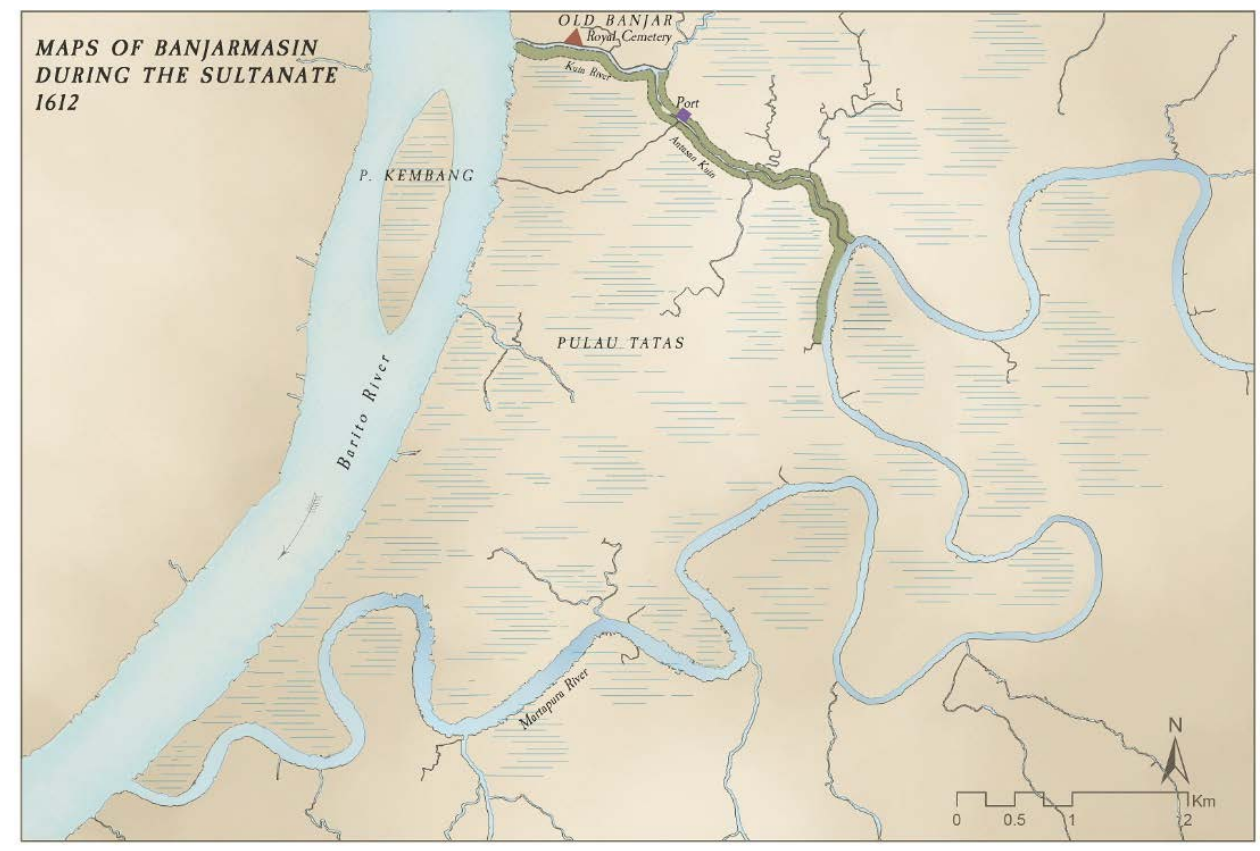

Gambar 5. Rekonstruksi peta Banjarmasin tahun 1612 sebagai pelabuhan sekunder

\subsubsection{Kota pelabuhan utama kesultanan (1663-1787)}

Meningkatnya volume perdagangan telah memicu terjadinya konflik internal perebutan kendali dagang dalam kesultanan yang memunculkan dualisme kekuasaan: Pangeran Ratu di keraton Kayu Tangi di daerah hulu, dan Pangeran Dipati Anom di Banjar Lama. Posisi Banjar Lama di daerah hilir lebih strategis sebagai titik temu para pedagang dari hulu dan seberang lautan sehingga Dipati Anom memegang kendali perdagangan kesultanan. Dengan demikian Banjar Lama kembali menjadi pelabuhan utama kesultanan sekaligus pusat pemerintahan. Pangeran Dipati Anom (r. 1663-1679) menjalankan pemerintahannya pada sebuah 'istana terapung' yang serupa dengan struktur benteng dilengkapi dengan meriam (Bataviaasch Genootschap van Kunsten en Wetenschappen, 1891). Struktur ini diperkirakan menjadi elemen sentral dalam lanskap Banjar Lama yang menandakan kembalinya fungsi politik di area ini. 
Setelah kekuasaan Dipati Anom berakhir diperkirakan terjadi perpindahan pemerintahan ke Martapura sementara pelabuhan beralih dari Banjar menuju Tatas. Tatas berada di sebelah selatan Banjar Lama yang dibatasi oleh Sungai Kuin di sebelah utara, Sungai Martapura di sebelah timur dan selatan, dan Sungai Barito di sebelah barat; sehingga Tatas menyerupai sebuah pulau dan dikenal sebagai Pulau Tatas. Sultan memiliki kediaman di Tatas dan sesekali ia berlayar dari keraton Martapura menuju Tatas untuk berbagai tujuan salah satunya melakukan negosiasi dagang dengan para pedagang asing (De Roy, 1706; Valentijn, 1726). Diperkirakan kediaman sultan tak jauh dari pertemuan antara Sungai Kuin dan Martapura, dan dekat dengan pelabuhan utama kesultanan. Tak jauh dari kediaman sultan terdapat sebuah pos jaga di tepi sungai dilengkapi dengan meriam dan rantai besi sebagai pertahanan yang membentang di atas Sungai Martapura (Müller, 1857).

Kondisi lanskap 'negeri Tatas' dalam konteks struktur kota diperkirakan tak berbeda jauh dengan ibu kota Kayu Tangi sebagaimana dikemukakan dalam hasil studi kesejarahan Johannes Willi Gais (1922). Daniel Beckman, seorang pedagang Inggris yang berkunjung di tahun 1714 melaporkan bahwa Kayu Tangi memiliki struktur kota linear di sepanjang Sungai Martapura sepanjang sekitar 4 mil atau 7,41 km. Bantaran sungai kebanyakan dihuni para elit kesultanan sementara penduduk tinggal di rumah lanting (Beckman, 1718). Kondisi ini menunjukkan pemanfaatan ruang di Tatas untuk berbagai fungsi kehidupan berlangsung di bantaran dan di atas sungai.

Sebagaimana kota-kota pelabuhan di Asia Tenggara pada umumnya, dari aspek sosial-budaya kota pelabuhan Banjarmasin merupakan kota kosmopolitan yang ditandai dengan penghuni kota yang majemuk, terutama dari sisi etnis (Reid, 1980). Keragaman ini disebabkan para pedagang intersular, regional, maupun internasional bermukim di kota ini, baik secara permanen maupun temporer. Mereka tinggal mengelompok membentuk kampung-kampung berdasarkan etnik dan asalnya, seperti misalnya kampung Jawa, Bugis, Arab, Melayu dan Cina. Selain itu terdapat pula pos dagang Inggris dan Belanda dimana mereka menambatkan kapal dan memiliki gudang penyimpanan komoditas dagang yang biasanya berupa rumah terapung atau yang dikenal sebagai rumah lanting.

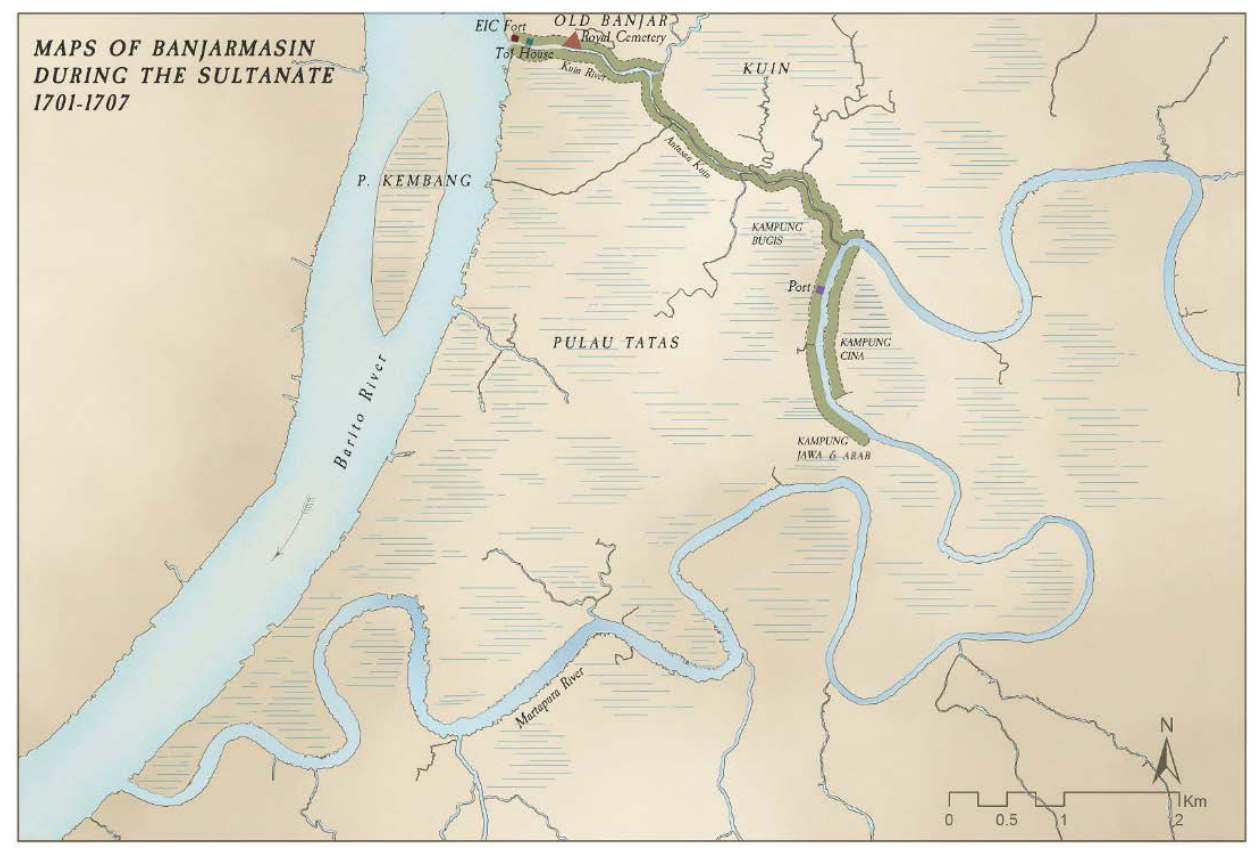

Gambar 6. Rekonstruksi peta Banjarmasin di awal abad ke-18

Di masa itu, para pedagang asing dapat tinggal di kota atas seijin sultan sebagai bagian dari transaksi dagang. Dalam berbagai sumber kesejarahan, pedagang dari Cina, Belanda dan Inggris merupakan tiga kelompok pedagang asing yang sering bersaing dalam perdagangan lada. Para pedagang Cina yang biasanya datang dengan kapal junk- menjalin hubungan dagang yang baik dengan sultan dan masyarakat dan diperbolehkan 
tinggal di sebelah timur Sungai Martapura di seberang Pulau Tatas, di abad ketujuhbelas (Chang, 1954; Fong, 1970). Para pedagang Cina yang menetap membuka toko-toko di atas lanting di Sungai Martapura (Schwaner, 1853; Müller, 1857) (Gambar 7). Pedagang Inggris utusan EIC (East Indian Company) pernah diijinkan mendirikan benteng melalui kesepakatan dengan sultan pada 1704 . Namun benteng yang nyaris selesai dibangun di utara muara Sungai Kuin tersebut diserang dan musnah pada 1707 atas perintah sultan. Pada periode selanjutnya para pedagang Inggris hanya diperbolehkan mendirikan pos dagang di Tatas (ANRI Jakarta, 1707; Beckman, 1718; Gais 1922).

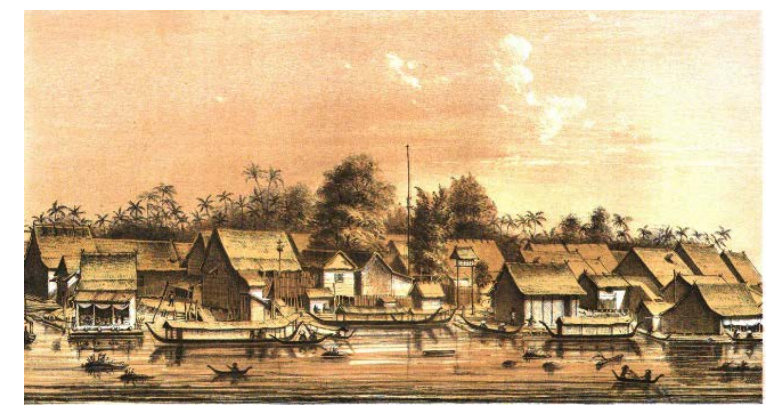

Gambar 7. Kampung Cina di sebelah timur Sungai Martapura di seberang Tatas (Schwaner, 1853)

Demikian pula halnya dengan pedagang Belanda dari VOC, pada mulanya hanya diijinkan membuat pos dagang. Pada tahun 1747 , setelah VOC mengirim bantuan militer untuk menghadapi pemberontakan, sultan mengijinkan pedagang Belanda membangun benteng. Oleh karenanya mereka membeli sebidang tanah di Tatas -dengan lingkungan rawa- di seberang kampung pedagang Cina, seluas sekitar $700 \mathrm{~m}^{2}$ untuk mendirikan sebuah pos militer dan kantor dagang.

Dapat dikatakan bahwa periode ini menandai munculnya kota Banjarmasin pada lokasi seperti yang kita kenal saat ini. Dengan meningkatnya kunjungan para pedagang dari berbagai asal, Tatas berkembang sebagai kota pelabuhan yang diikuti dengan pertumbuhan permukiman multi-etnis. Untuk mendukung aktivitas perdagangan, salah satu intervensi yang signifikan pada lanskap yaitu dibuatnya kanal yang memotong salah satu meander Sungai Martapura yang kala itu bernama Antasan Kiai Baria yang kemudian membentuk muara Sungai Kelayan dan Pekapuran (Saleh, 1983) (Gambar 8). Pada awal abad ketujuhbelas, para pedagang asing mengenal Tatas sebagai Banjarmasin (Beckman, 1718), dan perlahan-lahan istilah Banjar Lama tidak terdengar.

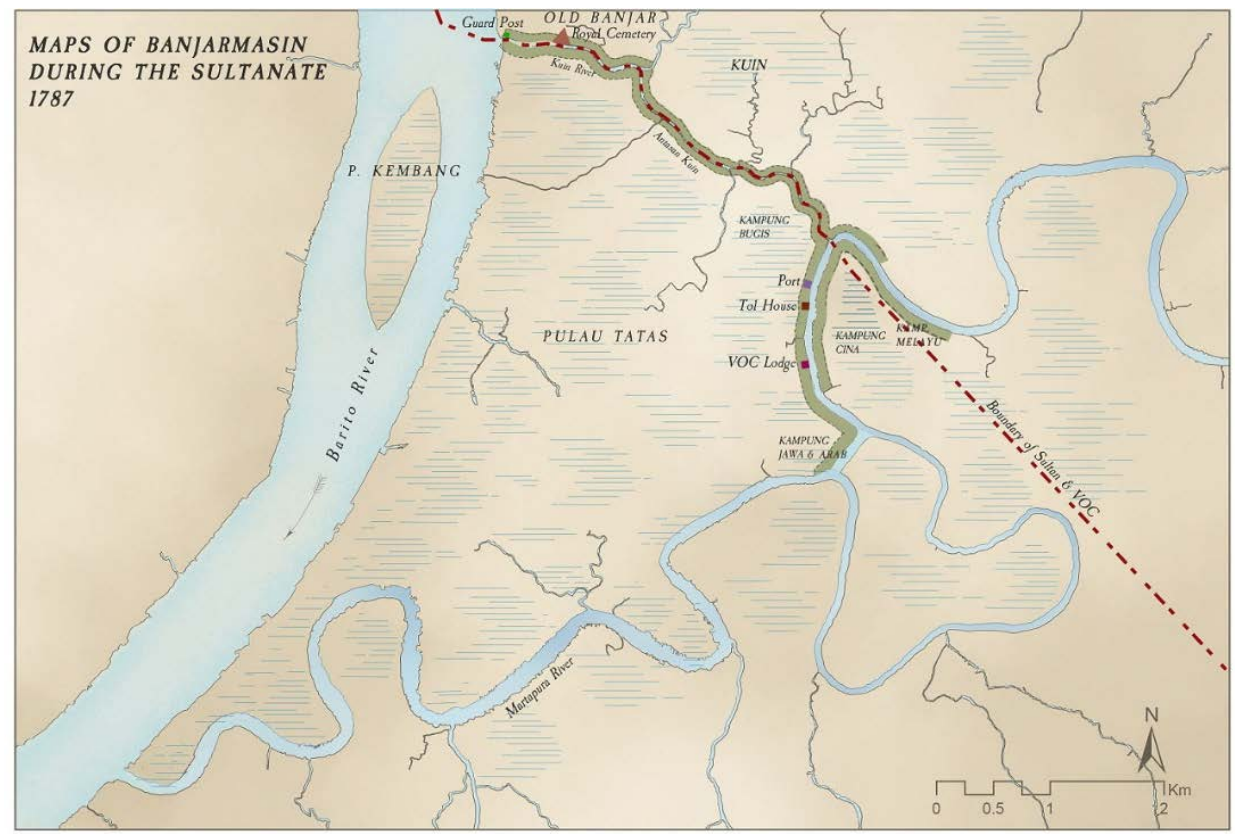

Gambar 8. Rekonstruksi peta Banjarmasin periode 1787 


\subsubsection{Kota pelabuhan utama Belanda di Kalimantan tenggara (1787-1860)}

Seiring berjalannya waktu, pengaruh VOC dalam bidang politik dan perdagangan kesultanan meningkat sebagai dampak dari bantuan militer dari Belanda kepada sultan dalam menghadapi pemberontakan dan perang yang berkepanjangan. Setelah pada tahun 1756 sultan menjadi vasal Belanda, maka pada 1787 disepakati sebuah kontrak yang menyebabkan wilayah kesultanan terbagi atas wilayah sultan dan wilayah VOC. Di Banjarmasin kedua wilayah ini sebagian dibatasi oleh Sungai Kuin dan Sungai Martapura.

Dengan adanya kontrak tersebut, Belanda memiliki kuasa penuh untuk mengatur wilayahnya dalam segala sektor, termasuk dalam mengembangkan lanskap. Untuk meningkatkan perdagangan dan memperkuat pertahanan, Belanda memperbaiki kamp Tatas. Pada tahun 1806 dibuat rencana pembangunan benteng yang lebih permanen -yang dikenal sebagai Benteng Tatas- yang terdiri dari barak militer, rumah residen, dan gudang. Sebuah pelabuhan beserta rumah cukai dibuat tak jauh dari benteng. Berbeda dengan struktur bangunan vernakular Banjar berupa rumah panggung di atas bantaran sungai atau rawa, Belanda menerapkan tradisinya dalam konstruksi bangunan, dimana benteng ini dibangun di atas lahan rawa yang diurug sehingga permukaan tanahnya kering karena lebih tinggi daripada rawa. Hal ini kemungkinan bertujuan untuk efisiensi kegiatan dalam benteng, seperti misalnya kegiatan artileri dan peletakan meriam (Van der Kemp, 1899; NA Den Haag, 1818, 1822).

Karena okupasi di Banjarmasin secara ekonomi dianggap tidak lagi menguntungkan, maka pada tahun 1809, Belanda meninggalkan Banjarmasin dan menjual Benteng Tatas dan Benteng Tabanio (sebuah benteng di muara Sungai Barito) kepada sultan seharga 25.000 real. Atas permintaan Sultan, Inggris melalui EIC kemudian mengantikan posisi Belanda ditahun 1812. Namun okupasi EIC berlangsung singkat, dengan ditandatanganinya Perjanjian London (London Treaty) antara Inggris dan Belanda yang menyebabkan Belanda kembali menguasai Hindia Belanda. Inggris meninggalkan Banjarmasin pada akhir 1816 dan Belanda, diwakili oleh Van Boekholtz, mengambil alih Banjarmasin setelah kesepakatan dengan sultan Soleiman Saidullah ( $r$. 1801-1825) ditandatangani pada 1 Januari 1817 di ibukota Karang Intan (Van der Kemp, 1899; ANRI, 1968).

Belanda kembali melakukan pengembangan wilayahnya yang pada dasarnya bertujuan memperkuat posisinya di Banjarmasin untuk mendukung keberhasilan usaha dagangnya yang tidak lagi bergantung pada lada. Kebijakan dan program yang dilaksanakan oleh Belanda membawa dampak pada perubahan lanskap Banjarmasin. Perubahan signifikan yang terjadi yaitu Belanda mulai mengembangkan area di luar benteng, seperti dengan dibangunnya kantor residen, pelabuhan dan gudang baru. Pos-pos keamanan dibangun terutama pada muara-muara sungai yang dianggap potensial menimbulkan permasalahan penyelundupan dan serangan perompak sungai. Beberapa diantaranya yaitu pos di muara Sungai Kuin dan Kelayan, selain sebuah benteng kecil di muara Sungai Martapura yang diberi nama Schans Van Thuijl (Gambar 9 dan 10).

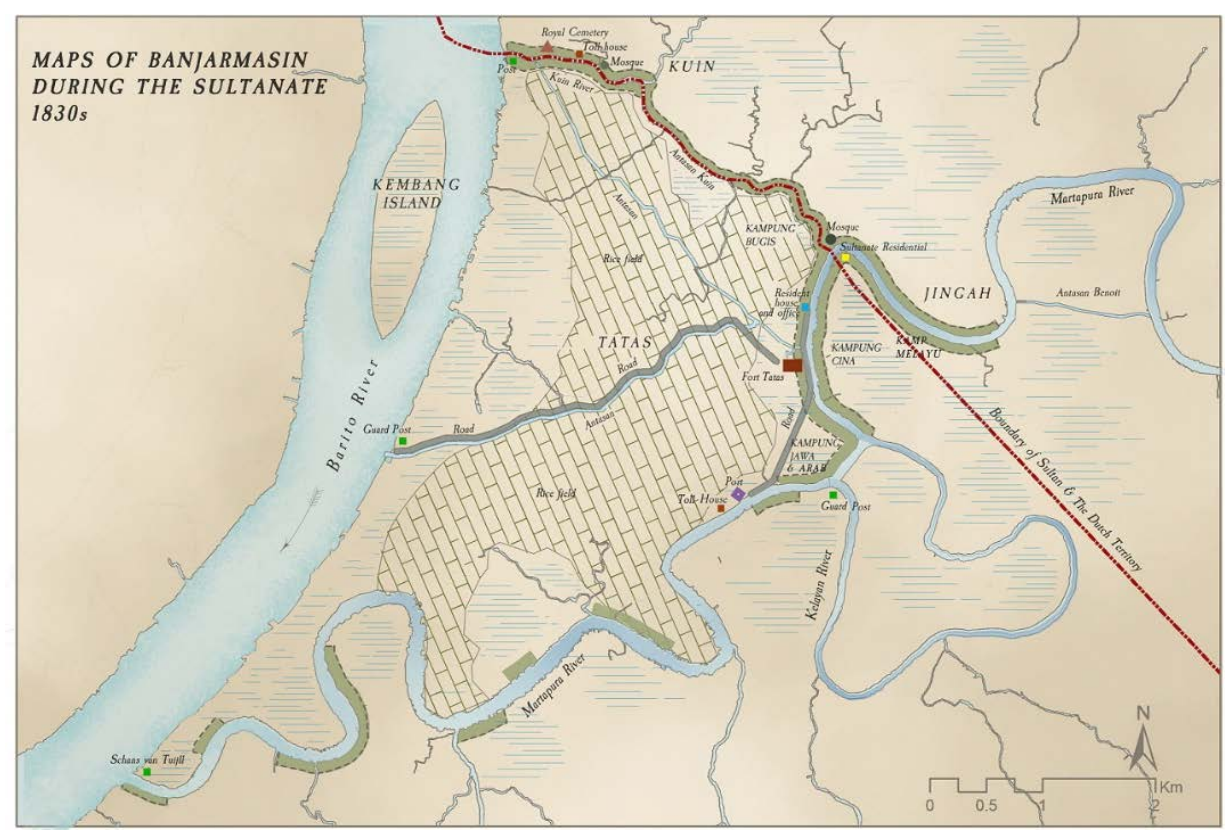

Gambar 9. Rekonstruksi peta Banjarmasin periode 1820-1830 


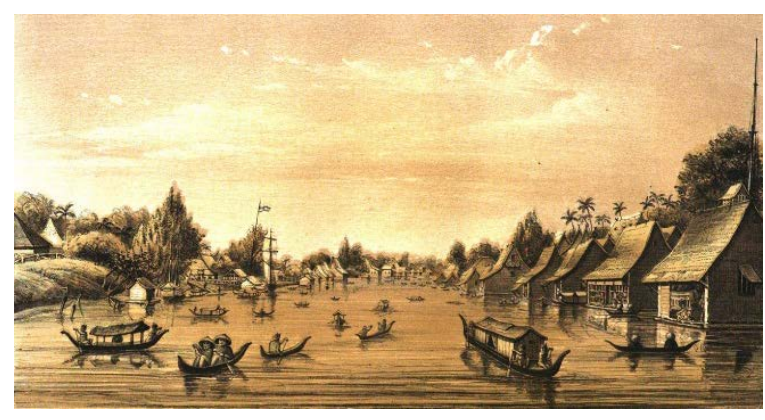

Gambar 10. Suasana Sungai Martapura di Banjarmasin dengan Benteng Tatas dan pelabuhan milik Belanda di sebelah kiri dan Kampung Cina dengan toko-toko terapung di sebelah kanan (Schwaner, 1853)

Berbagai intervensi lanskap yang dilakukan oleh Belanda berdampak pada perubahan lanskap. Pemanfaatan rawa tak hanya memunculkan penggunaan baru berupa lahan pertanian ekstensif di Tatas (Knapen, 2001), namun juga perlahan-lahan mempengaruhi menurunnya populasi vegetasi rawa serta mengindikasikan penggunaan ruang yang tidak lagi terfokus di bantaran sungai. Meskipun demikian, kegiatan berbasis sungai tetap mendominasi mengingat konstruksi jalan masih sangat terbatas. Kegiatan pengembangan memunculkan elemen-elemen lanskap baru, terutama benteng, jalan, kanal, jembatan, dan sawah. Benteng Tatas muncul menjadi pusat kota yang secara semantik menyimbolkan kekuasaan Belanda di Kalimantan bagian tenggara yang awalnya merupakan wilayah kesultanan Banjar. Kondisi ini berlangsung hingga tahun 1860 manakala Belanda menghapus kesultanan karena pemerintahan kesultanan dianggap tidak berfungsi akibat konflik politik internal kesultanan yang diintervensi oleh Belanda. Berakhirnya masa kesultanan menandai dimulainya periode kolonial yang kemudian merubah lanskap kota Banjarmasin menjadi sebuah kota kolonial (Gambar 3).

\section{Simpulan}

Lanskap kota Banjarmasin dan perubahannya selama periode kesultanan dipengaruhi oleh key processes yang pada dasarnya berhubungan dengan aspek politik ekonomi perdagangan. Struktur kota terbangun dengan adanya fungsi pemerintahan, ekonomi, dan sosial-budaya yang membentuk tipologi sebuah kota pelabuhan. Banjarmasin memiliki pola pemanfaatan ruang linear yang terbentuk sebagai respon manusia dalam memenuhi kebutuhannya terhadap kondisi alami lanskap yang didominasi oleh lingkungan rawa dan sungai. Pemanfaatan ruang secara intensif tidak hanya pada tepian sungai namun juga pada badan sungai yang menjadi jalur transportasi utama dan memfasilitasi aktivitas ekonomi. Interaksi manusia dengan lanskap alami Banjarmasin menghasilkan sebuah kota di atas air.

Perubahan lanskap Banjarmasin dalam konteks ruang (space) dan elemen pengisinya (material, form) menunjukkan bahwa selain kompleks keraton, maka pelabuhan beserta rumah cukai dan syahbandar merupakan elemen lanskap yang penting pada periode ini. Penguasaan terhadap pelabuhan dagang secara tidak langsung menandakan dominasi kekuasaan politik ekonomi. Studi identifikasi struktur lanskap dan perubahannya ini menghasilkan transformasi kota Banjarmasin sebagai berikut: (1) kota pelabuhan sekaligus pusat pomerintahan (port-polity) kesultanan (1526-1612); (2) kota pelabuhan sekunedr kesultanan (16121663); (3) pelabuhan utama kesultanan (1663-1787); dan (4) pelabuhan utama Hindia Belanda di Kalimantan Tenggara (1787-1860). Setelah 1860, lanskap kota berubah dengan karakter kota kolonial.

\section{Ucapan Terima Kasih}

Terima kasih kepada Lembaga Pengelola Dana Pendidikan yang telah memberikan beasiswa dan membantu pendanaan penelitian ini.

\section{Daftar Pustaka}

Ahyat, I.S. 2012. Kesultanan Banjarmasin pada Abad ke-19: Ekspansi pemerintah Hindia-Belanda di Kalimantan. Serat Alam Media, TangSel.

ANRI. 1963. Surat-surat Perdjandjian antara Kesultanan Bandjarmasin dengan Pemerintah2 VOC, Bataafse Republik, Inggeris dan Hindia Belanda 1635-1860. ANRI, Jakarta. 
BAPPEKO Banjarmasin. 2006. Revisi Rencana Umum Tata Ruang Kota (RUTRK) Banjarmasin 2001-2011. Badan Perencanaan Pembangunan Kota (BAPPEKO), Banjarmasin.

Bataviaasch Genootschap van Kunsten en Wetenschappen. 1891. Dagh Register Gehouden int Casteel Batavia vant passerende daer ter plaetse als over geheel Nederlandts-India, Anno 1663. G. Kolff, Batavia.

Beckman, D. 1718. A Voyage to the Island of Borneo in the East-Indies. T Warner, London.

Chang, T.K. 1954. Historical Geography of Chinese Settlement in the Malay Archipelago. Disertasi Univ. of Nebraska (tidak dipublikasikan).

De Roy, J.J. 1706. Voyaagie gedaan door Jacob Janssen de Roy, na Borneo en Atchin, in 't jaat 1691 en vervolgens. Pieter vander Aa, Batavia.

Fong, C.Y. 1970. The Chinese in Banjarmasin during the first half of the eighteenth century. Journal of the Historical Society, Univ. of Malaya Vol 8.

Gais, JW. 1922. The early relations of England with Borneo to 1805. H Beyer, Langensalza.

Ganie, T.N. 2011. Sejarah kehidupan di Tanah Banjar. Tuas Media, Martapura.

Knapen, H. 2001. Forests of Fortune? The environmental history of Southeast Borneo, 1600-1880. KITLV Press, Leiden.

Marcucci, D.J. 2000. Landscape history as a planning tool. Landscape and Urban Planning 49: 67-81. https://doi.org/10.1016/S0169-2046(00)00054-2

Müller, S. 1857. Reizen en onderzoekingen in den Indischen Archipel, gedaan op last der Nederlandsche Indische regering, tusschen de jaren 1828 en 1836. Vol. 1. F Muller, Amsterdam.

Ras, J.J. 1968. Hikajat Bandjar: A study in Malay Historiography. Martinus Nijhoff, The Hague.

Reid, A. 1980. The Structure of Cities in Southeast Asia, Fifteenth to Seventeenth Centuries. Journal of Southeast Asian Studies Vol. 11 (2): 235-250.

Reid, A. 1993. Southeast Asia in the Age of Commerce, 1450-1680. Vol. 2, Expansion and Crisis. Yale Univ. Press, New Haven.

Saleh, M.I. 1982. Banjarmasih. Museum Negeri Lambung Mangkurat, Banjarbaru.

Schwaner, C.A.L.M. 1853. Borneo, Vol I. PN van Kampen, Amsterdam.

Spirn, A.W. 1998. The Language of Landscape. Yale Univ. Press, New Haven and London.

Subiyakto, B. 2004. Infrastruktur Pelayaran Sungai Kota Banjarmasin Tahun 1900-1970. Prosiding, The first International Conference on Urban History.

Sumawinata, B. 1998. Sediments of the Lower Barito Basin in South Kalimantan: Fossil Pollen Composition. Southeast Asian Studies 36(3): 293-316. http://hdl.handle.net/2433/56685

Valentijn, F. 1726. Oud en nieuw Oost-Indiën Deel III, Part 2. Joannes van Braam, Amsterdam.

Van der Kemp, H. 1898. Het Afbreken van Onze Betrekkingen Met Bandjermasin Onder Daendels en de Herstelling van Het Nederlandsch Gezag Aldaar op den 1 N Januari 1817. Bijdragen Tot De Taal-, Land- En Volkenkunde Van Nederlandsch-Indië, 49(1) :1-168.

Van Dijk, L.C.D. 1862. Neêrlands vroegste betrekkingen met Borneo, den Solo-Archipel, Cambodja, Siam en Cochin-China: een nagelaten werk. JH Scheltema, Amsterdam.

Van Wijk, .CL. 1951. Soil Survey of the Tidal Swamps of South Borneo in Connection with the Agricultural Possibilities. Ministry of Agriculture, Bogor.

\section{Dokumen arsip}

ANRI Jakarta (Arsip Nasional Republik Indonesia, Jakarta), Marginalia to the Daily Journals 1659-1807, file 2531 folio 499-50, Item een rapport van den ondercoopman Jan de Wolf wegen desselfs wedervaren tot Banjar, 18 July 1707.

NA Den Haag (Nationaal Archief, Den Haag), Collectie 460 J.B. Osten, 2.21.205.45, inv.nr. 9, Rapporten betreffende de forten en posten te Bandjermassin, 1818, 1822. 